\title{
Analyzing the Findings of the Saudi Research on Student Attrition in Higher Education
}

\author{
Othman Aljohani ${ }^{1,2}$ \\ ${ }^{1}$ School of Education, RMIT University, Melbourne, Australia \\ ${ }^{2}$ English Language Centre, Institute of Public Administration, Jeddah, Saudi Arabia \\ Correspondence: Othman Aljohani, English Language Centre, Institute of Public Administration, Jeddah, Saudi \\ Arabia. E-mail: johanio@ipa.edu.sa
}

Received: January 8, 2016

Accepted: February 16, 2016

Online Published: July 26, 2016

doi:10.5539/ies.v9n8p184

URL: http://dx.doi.org/10.5539/ies.v9n8p184

\begin{abstract}
This paper presents a comprehensive review of the available literature on student attrition in Saudi higher education context. Despite the reported low student retention rates in Saudi tertiary institutions, student attrition remains an under-researched phenomenon. Thus, this paper aims to trace and collect all the available studies that addressed the issue of low student retention in the Saudi in higher education and to present and analyse their findings. This will help in providing evidence and empirical data that give a clearer view of the problem and pave the way for the future researchers as well as allowing for suggestions towards more effective plans and solutions. The student attrition factors reported in the reviewed Saudi studies were classified under personal, academic, social and institutional categories. However, the students' low academic abilities and institutional factors were the most common across all of the studies. These factors relate to students' experiences with the administrative system of their academic institution, including the admission, registration and disciplinary rules and policies and the availability and quality of student services and facilities.
\end{abstract}

Keywords: higher education, student retention, attrition, persistence

\section{Introduction}

Student attrition is a serious issue in education around the world. Schools and higher education institutions has been causing schools and higher education institutions concern since the establishment of formal education. In Saudi higher education, low student retention is a critical issue. The average graduation rate for many tertiary institutions is $65 \%$ among students of four-year programs and between $35 \%$ and $50 \%$ among those in two-year programs (Ahmad, 2011; Alroshod, 2009; Bagazi, 2010; Institute of Public Administration, 2012; Riyadh Economic Forum, 2011). These numbers show that the low student retention issue exists at all levels of higher education in Saudi Arabia.

Despite these low student retention rates, student attrition remains an under-researched phenomenon in the Saudi higher education context. After a comprehensive search in all available sources, only 15 studies were found that focus in Saudi higher education context. Thus, this paper aims to trace and collect all the available studies that addressed the issue of low student retention in the Saudi in higher education and to present and analyse their findings. This will help in providing evidence and empirical data that give a clearer view of the problem and pave the way for the future researchers as well as allowing for suggestions towards more effective plans and solutions.

\section{The Scope of the Paper}

As mentioned earlier, few studies have been conducted in the Saudi higher education context that addresses the student attrition problem. Al-Dossary (2008), in his study of the student attrition factors at King Saud University, said that 'there is currently no study which has examined the retention of Saudi students' (p. 11). While some retention studies in the Saudi higher education context have since been published, many of the available Saudi retention studies are government and institutional reports that are limited to reporting student retention, attrition and graduation rates and statistics without any analysis. This is problematic, as decisions regarding low student retention in Saudi higher education institutions might be based on these statistics and rates rather than on in-depth investigations of the factors that cause the problem. 
Compounding the problem of the paucity of Saudi student retention studies, many are inaccessible to researchers. This is due to the restrictions in publishing, obtaining and borrowing doctoral and masters theses from Saudi universities and the lack of academic databases and thesis repositories (Note 1) (Alabullateef, 2008). While some empirical studies investigating the problem of student attrition in the Saudi higher education have recently started to be published, a careful online search of all available Saudi academic databases and university websites and other Arabic and international databases returned only 16 theses, dissertations, reports and studies focusing on student attrition in the Saudi higher education context between 1986 and 2014.

Only 11 of these were available and accessible online and so could be reviewed in this paper (Abuelma'atti, 2006; Al-Abdulkareem, 2012; Al-Dossary, 2008; Al-Ghnaim, 2010; Alabdulgader, 1992; Aljohani, 2014; Fayed \& Gasem, 2012; Hakeem, 2007; Khan \& Osman, 2011; Malah, 1994; Mobarak, Alharthi, \& Kees, 2000). The other five studies were only available as online abstracts and were thus excluded (Abdullaal, 2010; Alabdullah, 1995; Almaneea, 2003; Felemban, 1986; Ghaban, 1999). A further two Saudi student retention studies were excluded from the review, as they focused on student retention in online courses, which is outside the scope of this paper (Dahan, 2008; Ibrahim, Rwegasira, \& Taher, 2007).

Certainly, 11 studies seems a small number compared to the size of the Saudi higher education sector as described in Chapter Two. However, these studies investigated the low retention phenomenon among the students of both two-year and four-year Saudi higher education institutions. The following section presents a comprehensive review of all of the available Saudi retention studies.

\section{Methodology}

As the main purpose of this paper is to list the most common student attrition factors that were found by the Saudi studies The data was analysed in a descriptive way using thematic analysis approach. Thematic analysis can be defined as 'a method for identifying, analysing and reporting patterns (themes) within data' (Braun \& Clarke, 2006, p. 79). Bryman (2008) described thematic analysis as the process of extracting the key themes from the data. According to Creswell (2012), themes are major ideas in the database formed by the process of grouping similar codes, which are the 'labels used to describe a segment of text or an image' (Creswell, 2005, p. 238).

To achieve this, the student attrition factors were identified and their frequencies were calculated based on the institution level (two-year and four-year) and then in total to identify the student attrition factors across Saudi studies. Subsequently, these attrition factors were classified according to their similarities under bigger themes.

\section{The Available Saudi Student Retention Studies}

This following section present and review the few published studies that investigated the student attrition phenomenon in the Saudi higher education context. These studies are considered chronologically.

The study of Alabdulgader (1992) on the factors contributing to student attrition in the Saudi higher education sector appears to be the oldest available Saudi student retention study. Alabdulgader (1992) studied the factors associated with the student attrition phenomenon in Saudi universities as perceived by students and faculty staff of universities and tertiary colleges in the Eastern province of Saudi Arabia (nine academic institutions). The statistical analysis included student data from all Saudi universities. The study sample included both voluntary non-persister students and academically dismissed students.

Alabdulgader's (1992) study aimed to define student attrition and retention and to measure the rates of student attrition in tertiary institutions in Saudi Arabia and government spending on higher education programs. Moreover, the study aimed to find the most frequent factors associated with the student attrition phenomenon in Saudi higher education. To do this, a 78-item questionnaire was designed to collect information on the personal, family, social and economic and educational factors affecting student attrition, based on the findings of previous studies. Responses to the study instrument ( $\mathrm{n}=395)$ were analysed using the descriptive analytical method.

The study found that student attrition rates were dependent on students' study majors. The student attrition rates across all Saudi tertiary institutions range between 20 and 68\%. However, at 50-68\%, the attrition rates were higher for science majors. For the social and literature study majors, on the other hand, the rates were between 20 and $37 \%$. In regard to loss of government spending on higher education, the study found that the student attrition problem cost $43 \%$ of the total annual Saudi higher education budget.

The factors found by the study to relate to the student attrition phenomenon were grouped under the following categories: personal, family, social and economic and educational. The personal factors included gender, age and emotional status; while the family factors included maternity, preparing for marriage, family relationships, parents' divorce, death of one or both parents and family income. The social and economic factors included 
social integration, life commitments, financial crises, transportation, friends' commitments and home sickness. Finally, the educational factors included pre-entry academic ability, admission policy, low English language skills, weak preparation for higher education, lack of social integration into the university environment, financial support, class size and relationship with the university administration.

Two years later, Malah (1994) studied the student attrition factors in Saudi technical colleges (formerly, intermediate technical colleges). The study aimed to identify the main motivators of students to leave their study programs before completion and how this related to students' educational and occupational goals and their awareness of the importance of vocational and technical education. The study also focused on the impact of other background factors such as students' previous qualifications, students' social and residential status and the educational levels of their parents.

The study utilised student questionnaires for the data collection, which were then analysed quantitatively. The sample of the study was limited to the students of Riyadh Intermediate Technical College (currently known as Riyadh College of Technology) in the academic year of 1990. In that year, 16\% of first-year students voluntarily withdrew from their study programs before graduation. The factors that led them to withdrew, as found by the study, were as follows:

\section{- Transferring to four-year institutions}

- Found a job

- Poor orientation to the vocational education system

- High secondary school grades

- Parents' level of education

- Home sick (especially for non-resident students)

- Family crisis

An important finding of this study was the correlation between non-persister students' secondary school grades and the educational level of their parents and their educational and occupational future after withdrawal. Specifically, the study found that students with higher secondary school grades and/or whose parents attained a higher educational level tended to leave the two-year college to transfer to better academic institutions. Conversely, those students with lower secondary school grades and/or whose parents had a lower educational level tended to leave to find a job or withdraw completely from the higher education system. Moreover, the majority of non-persister students $(65 \%)$ reported having no idea about the technical and vocational education system and the job opportunities and future of the graduates from this system.

A field study was conducted in Umm Al-Qura University by Mobarak et al. (2000) to collect information from the students and faculty staff about the factors that lead some students to fail and/or withdraw from their study programs. The student participants were limited to male students that had failed some courses during their study programs (at risk students) and who had GPAs of less than one out of four points, or those that had withdrawn from the university between the academic years of 1987 and 1997.

The researchers utilised three different questionnaires to collect information from these three different participant groups, which numbered 110 non-persister students, 130 at risk students and 136 faculty members. The statistical analysis of the participants' responses revealed that both student groups and the faculty members listed some personal, social and institutional factors that might affect students' experiences in their study programs and lead them to fail or withdraw. As the focus of the current study is on the student attrition problem, only those factors that were identified as leading students to leave their study programs before completion are considered here.

Student participants reported that the most frequent factors that affected their withdrawal decisions were the difficulties in choosing the desired study majors, lack of academic advising, life commitments and friends' influence. Moreover, the students reported that university was not their first choice and that they had enrolled either because it was the only available opportunity after high school or because it was their parents' preference. Faculty members agreed with the student participants that the inability to enrol in the desired study major was one of the most influential factors leading students to withdraw from their study programs. Moreover, they viewed social commitments and financial crises as the other important factors affecting students' persistence at Umm Al-Qura University.

A more recent study is that of Abuelma'atti (2006) on the problems facing engineering education in the Saudi higher education context. The paper focused on student retention, attrition and graduation rates. Although the scope of the paper was all Saudi universities and technical colleges that provide engineering education, specific 
statistics on student retention, attrition and graduation rates were presented for the King Fahd University of Petroleum and Minerals, one of the largest and most prestigious universities in Saudi Arabia. The statistics showed that in 2004 the number of students who left the university without a degree was higher than the number of graduated students in the same year. In that year, 732 students withdrew before completion compared to 658 who managed to graduate. However, only 50 students withdrew for non-academic reasons; the remainder left or were asked to leave due to weak academic performance. Of the 1781 students enrolled in the university's foundation program in the same year, 345 students were academically dismissed and 40 students voluntarily withdrew for other reasons.

Abuelma'atti concluded that the major causes of student attrition from Saudi tertiary engineering education programs could be classified under the following factors:

- Poor educational skills and abilities, especially in science and English

- Poor educational commitment

- Heavy learning loads

- Poor academic integration

- Poor teaching quality, including untrained teachers and poor course administration

- Poor admission and registration policy, including poor student orientation, poor preparation for the transition to higher education level and lack of student advising and support

- Personal problems.

In 2007, Hakeem studied the student attrition factors in Makah Teachers College. The study sample was 70 students who withdrew from the college in the academic years of 2004 and 2005 (Hakeem, 2007). The sample was limited to those students who had GPAs higher than 2.0 points at the time of withdrawing, to exclude students who had been academically dismissed. The study was quantitative and utilised statistical analysis techniques. Based on the literature, the study instrument was limited to five dimensions: personal, academic, family and external factors and student-faculty relationships. The statistical analysis of the participants' responses aimed to identify the impact of these variables on the student attrition problem.

The study found that the main factors that affected student retention in Makah Teachers College could be classified under the categories of personal, academic and student-faculty relationships. The non-persister students showed lower motivation towards higher education, lower academic integration and poorer relationships with the academic staff. Other factors from other categories that were important but to a lesser degree included family commitments and problems, external commitments and students' thinking about getting a job instead of studying.

Al-Dossary's (2008) $\mathrm{PhD}$ thesis on the factors affecting student retention at King Saud University was the first in-depth study that investigated the student attrition problem in the Saudi higher education context. In his study, Al-Dossary investigated the attrition phenomenon among the students of the first and largest Saudi university, King Saud University. The study was a comprehensive mixed methods study, guided by Tinto's Student Integration Model (1975). Both quantitative and qualitative methods were utilised in the collection and analysis of the study data. For the quantitative phase, two student questionnaires were used to collect data from 414 persister first-year students, with analysis conducted using the Structural Equation Modelling technique. Qualitative data were collected from 17 non-persister students (phone interviews), 15 persister students (focus group interviews) and 37 academic and administrative staff (surveys). The qualitative data were analysed using the Constant Comparative Analysis method (Maykut \& Morehouse, 1994).

The main findings of the study revealed that the constructs of Tinto's theoretical model did not explain the student attrition phenomenon in King Saud University. The statistical analysis showed that only $30 \%$ of the hypothesised variables of Tinto's theoretical model were supported by the participants' responses. These variables were the students' initial goal and institutional commitment, later goal and institutional commitment and pre-college schooling. These findings were supported by the qualitative data. As concluded by Al-Dossary, the analysis of the qualitative data showed that persister students were more motivated towards higher education and had higher levels of institutional commitment. In addition, the study found factors additional to those postulated in Tinto's theoretical model that might affect student retention in the Saudi higher education context. These factors were the difficulties in selecting or transferring to the desired study major, a lack of academic advice and the irregularity of the students' monthly allowance.

Al-Ghnaim's (2010) was the only student retention study conducted on a Saudi female campus. In her masters 
thesis, Al-Ghnaim investigated the attrition factors among the first-year female students at Imam Muhammad Ibn Saud Islamic University. The aim of the study was to identify the student attrition factors as perceived by the students and the university administrative staff. Al-Ghnaim utilised a quantitative descriptive method to analyse the responses of the 475 female students and 24 administrative staff who participated in the study.

The major findings of the study were classified by the researcher under the following categories: personal, academic and social. For these categories, the most important factors leading students to withdraw from their study programs as reported by both students and administrative staff were, respectively, maternity and low commitment to higher education, getting poor academic grades and family crisis. Moreover, administrative staff pointed to students' difficulty in enrolling in their desired study major as another major factor in student attrition.

In 2011, Khan and Osman presented a conference paper on the factors affecting students' satisfaction and retention at Dammam Community College (Khan \& Osman, 2011). The study aimed to investigate the causes of dissatisfaction among accounting and marketing students that led them to either withdraw from their study programs before completion or transfer to other institutions. The sample of the study was 74 students and six (Information Technology) IT staff. The study utilised a mixed methods approach for data collection and analysis. Student questionnaires were used to collect the quantitative data, while staff interviews were the instrument for the qualitative data. The quantitative data were analysed statistically using descriptive and regression analysis techniques, and the interviews were analysed qualitatively.

The major findings of the study attributed student dissatisfaction and subsequent attrition to the following factors: financial issues, employment, academic performance, scheduling, registration processes, administrative processes, classroom/lab and IT support services. The last factor had the strongest impact on the student attrition phenomenon at Dammam Community College.

In 2012, Fayed and Gasem (2012) investigated the relationship between the 'adjustment with university life' factors and the probability of student dropout. The study was conducted on the male campus of Imam Muhammad Ibn Saud Islamic University in Riyadh, Saudi Arabia. The study population were the undergraduate students from all colleges and study majors of the male campus. The study sought any significant differences between the 'adjustments with university life' factors and the probability of student dropout and tested the predictability of a scale to identify the students who are at risk of dropping out.

To achieve these aims, the researchers utilised a translated and modified version of the Adjustment to College Scale (Baker \& Siryk, 1983). The scale consists of four subscales that measure academic adjustment, social adjustment, personal and emotional adjustment and goal commitment. The study questionnaires were completed by 170 male participants from different colleges of the university, study levels and majors.

The statistical analysis of the participants' responses revealed that there is a negative significant relationship between most of the 'adjustment with university life' factors and the probability of student dropout. This means that the higher the level of student adjustment with university life, the lower the chance of dropping out. However, these significant statistical relationships were found only in the social and academic adjustment and goal commitment items. No significant difference was found in the study sample for the personal and emotional adjustment items. The study concluded with the statement that students who have a higher level of adjustment to the academic life of the college and have higher levels of goal commitment are usually at a lower risk of dropping out from their study programs.

In the same year, Al-Abdulkareem's (2012) conducted a masters thesis on the factors leading to the high attrition rates among trainees in Saudi technical colleges. According to Al-Abdulkareem, the graduation rate in the academic year of 2010 across all Saudi technical colleges was as low as $24.1 \%$ of the total number of students enrolling in the same year.

The study was limited to the views of the faculty members of the 36 Saudi technical colleges at the time of the study. A total of 246 responses were analysed quantitatively to identify the most frequent trainee attrition factors and to investigate the statistical differences between the participants' views based on their demographic characteristics. The main findings of Al-Abdulkareem's study attributed the student attrition phenomenon, as perceived by the faculty members, to three primary factors: the level of qualification (two-year diplomas), the students' poor institutional commitment and the low reputation of technical colleges in Saudi society.

Finally, the most recent available Saudi student retention study was Aljohani's (2014) PhD thesis that explored the factors influencing student retention at a tertiary English language centre in Saudi Arabia. The study was an exploration of the phenomenon of low student retention rates in an English language centre of a tertiary institution in Saudi Arabia. The aim was to investigate the factors affecting student retention and those to which 
non-persister students responded when making the decision to leave the sample college. The study also aimed to investigate the role of the institutional experience and whether there was a relation to students' academic ability in the English language.

The adopted research design was sequential exploratory mixed methods with greater emphasis on the qualitative phase. The study consisted of an initial qualitative phase and subsequent quantitative phase. Student data were collected during the academic year of 2012-2013 through interviews, focus groups, surveys and questionnaires for the quantitative data. The participants of the qualitative phase were four non-persister students (interviews), 15 persister students (focus groups), 10 academic and administrative staff (surveys) and 163 students who participated in the quantitative study questionnaires. The college records indicated that 53 of the sample students withdrew by the end of the first year of the program.

The thematic analysis of the qualitative data revealed that the main sources of student attrition were the students' poor institutional experience and satisfaction, particularly with the college administrative system; the poor level of their institutional commitment; and the high level of their educational and employment goals. These findings were tested quantitatively through a modified version of the Institutional Integration Scales (IIS) designed by Pascarella and Terenzini (1980) to check whether the qualitative data could be generalised to the larger population of the sample college.

The statistical analyses of the questionnaires confirmed that the non-persister students were significantly different from their persister counterparts in regard to many of the tested variables. They had significantly higher high school grades, higher levels of life and work commitment, lower levels of institutional commitment and lower levels of institutional integration according to their overall scores on the IIS. Moreover, the conclusion of the study suggested that the main motivator behind non-persister students withdrawing from the sample college was the availability to them of another study or job opportunity. No evidence was found to associate the student attrition phenomenon in the sample college with students' low academic ability, especially in the English language.

\section{Student Attrition Factors across Saudi Studies}

Table 3.2 lists the most frequent student attrition factors in the Saudi higher education context as found in the available studies reviewed in the previous section. The numbers in the table indicate how frequently these factors were found in the studies of two-year and four-year institutions, as well as in total. As shown in the table, although the attrition factors appear similar for both types of institution, it can be inferred from the conclusions of the reviewed studies that student attrition factors might be slightly dependent on the type and level of the institution. This is more obvious for the two-year institutions, for which transferring to four-year institutions and getting a job were the most frequently reported factors. The qualification level of the institution, the lack of students' knowledge about the differences between the two-year and four-year education systems and the types of jobs each system prepares students for played a major role in leading students to withdraw or transfer from two-year institutions.

For the four-year students, on the other hand, non-institutional factors such as the students' academic abilities and their level of motivation and educational commitment were the most frequently reported reasons for withdrawal. Moreover, two of the reviewed studies found that some students withdrew because of difficulties enrolling in or transferring to their desired study majors. However, this may be attributable to institutions' admission policy or students' pre-entry academic performance not meeting the requirements of entry to some study majors.

Table 1. Frequent student attrition factors in the Saudi higher education context

\begin{tabular}{llll}
\hline Factors & Two-year & Four-year & Total \\
\hline Institutions' rules and policies & 3 & 4 & 7 \\
Family commitments and problems & 2 & 5 & 7 \\
Poor academic integration & - & 4 & 4 \\
Financial issues & 1 & 3 & 4 \\
Low academic ability & 1 & 2 & 3 \\
Employment & 2 & 1 & 3 \\
\hline
\end{tabular}




\begin{tabular}{llll}
\hline Type and level of the institution & 4 & - & 4 \\
Poor educational commitments & - & 3 & 3 \\
Poor orientation & 2 & 2 & 4 \\
Friends' influence & - & 2 & 2 \\
The institution is not my first choice & 1 & 2 & 3 \\
Parents' level of education & 2 & - & 2 \\
Home sick (non-resident students) & 1 & 1 & 2 \\
Maternity & - & 2 & 2 \\
High secondary school grades & 2 & - & 2 \\
Personal problems & - & 1 & 1 \\
Poor teaching qualities & - & 1 & 1 \\
Low level of motivation & - & 1 & 1 \\
Lack of academic advice & - & 1 & 1 \\
Difficulty in choosing the desired study major & - & 1 & 1 \\
\hline
\end{tabular}

\subsection{Gender Differences in Saudi Retention Studies}

As stated before, all Saudi academic institutions are sex-segregated. Thus, investigating the differences between male and female students in regard to the research problem might enrich the Saudi student retention literature. Of those studies reviewed in this chapter, the majority were conducted at male institutions and campuses. Only one of the 10 studies was conducted on a female campus, of a four-year university.

In general, apart from maternity, which was one of the withdrawal reasons reported by the female participants of Al-Ghnaim (2010) and Alabdulgader's (1992) studies, the factors identified as affecting female students' retention were not different from those reported for the male participants of the other Saudi studies. The other student attrition factors found in the female only study (Al-Ghnaim, 2010) were related to the students' level of educational and family commitment and the level of their academic abilities, which were common factors in most of the reviewed studies. Thus, it can be concluded from the findings of the available Saudi retention studies that a student's gender does not have a significant influence on the student attrition phenomenon.

\section{The Research Gab}

The above comprehensive analysis of the conclusions of the Saudi student retention studies revealed some research gaps. These research gaps include both uncovered issues and issues that were studied using an inappropriate or inadequate method. However, the biggest gap identified by a review of the Saudi studies was the paucity of such studies. As reported above, despite the high rate of student attrition in Saudi higher education institutions, especially in two-year institutions, only 10 studies investigating this phenomenon in the Saudi context could be accessed for consideration in this study.

The analysis of these studies revealed some defects in the utilised research strategies and techniques. Some of the reviewed studies were statistical descriptive only (Abuelma'atti, 2006), while others relied solely on the perceptions of faculty staff without reporting the experiences of persister or non-persister students (Al-Abdulkareem, 2012). In addition, most of the reviewed Saudi studies, although not exploratory, were lacking in conceptual and theoretical background (Abuelma'atti, 2006; Al-Abdulkareem, 2012; Hakeem, 2007; Malah, 1994).

Another major gap in Saudi retention studies was the lack of studies on female tertiary institutions and campuses. As Saudi Arabia has a single-sex education system, researchers need to conduct their studies on two different campuses if they want to include both genders in their study samples. As mentioned above, out of the 10 available Saudi retention studies, only one study was conducted on a female campus and none of the above-reviewed studies included both genders in their samples. This might raise questions about the lack of information on the role of gender on student attrition in Saudi Arabia. However, the impact of gender on student attrition may be less important considering the views proposed by some studies that student attrition is primarily a campus-based phenomenon (Astin, 1984; Berger, Ramirez, \& Lyon, 2012; Tinto, 1993). 


\section{Conclusion}

To summarise the findings of the Saudi retention studies, student attrition factors can be classified as personal, social, academic and institutional. Personal and social factors are all those factors not related to the academic institution and its systems. These factors are related to students' personalities and their external communities, such as their financial situation, occupational and job commitments and family problems and commitments. Academic factors, on the other hand, can be related to individual students, such as in the case of the student's pre-entry or current academic performance, or to the academic systems of the institution. Finally, the institutional factors are those factors related to the institution's rules and policies, such as its admission policies and registration rules and the quality of the services, advice and facilities provided for students.

The institutional factors were found to contribute most significantly to the student attrition phenomenon in higher education in Saudi Arabia. These institutional factors, such as institutions' rules and policies, were reported in studies of both two-year and four-year institutions. While students' low academic abilities were reported as an important factor in three of the four-year studies, but not in the two-year studies, this factor is usually related to academic dismissal rather than to voluntary withdrawal. In contrast, it was found by one of the two-year studies that high academic ability can lead to students withdrawing from the institution to transfer to a better institution.

Regarding the gender of the students, although the student gender variable was not studied in all available Saudi retention studies due to the single-sex education system of the country, the comparison of the findings of the reviewed studies revealed that, apart from maternity, the factors identified by the reviewed studies, whether conducted in a male or female institution, were similar.

In conclusion, the findings of the studies conducted in the Saudi higher education context were not very different from those of the other international studies reviewed above. Although the factors reported in the reviewed Saudi studies were classified under personal, academic, social and institutional categories, the institutional factors were the most common across all of the studies. These factors relate to students' experiences with the administrative system of their academic institution, including the admission, registration and disciplinary rules and policies and the availability and quality of student services and facilities. Alongside this, another important factor was students' low academic abilities. However, this factor was primarily related to academic dismissal rather than to voluntary withdrawal, which is outside the scope of most retention theoretical models and studies, including the current study.

\section{References}

Abdullaal, A. (2010). الكفائة الداخلية للسنة التحضيرية بجامعة حائل في المملكة العربية السعودية، دراسة ميدانية [The internal efficiency of the preparatory year at the University of Hail in Saudi Arabia, a field study]. Arab Journal for Quality Assurance in Higher Education, 3(5), 46-73.

Abuelma'atti, M. (2006). Engineering education in Saudi Arabia: Problems and solutions. Paper presented at the The Fourth Saudi Technical Conference and Exhibition, Riyadh, Saudi Arabia. Retrieved from http://ipac.kacst.edu.sa/edoc/2007/162696_2.pdf

Ahmad, W. (2011, December, 19). 53 [Student attrition rate in vocational institutions rises to 53\%]. Alwatan Newspaper. Retrieved from http://goo.gl/Tuf1GL

Alabdulgader, A. (1992). عوامل الإهدار في التعليم الجامعي في الملكة العربية السعودية [Higher Education Attrition Factors in Saudi Arabia]. Paper presented at the Higher Education in Saudi Arabia the status and future prospects, Riyadh, Saudi Arabia. Retrieved from http://goo.gl/FfQNrZ

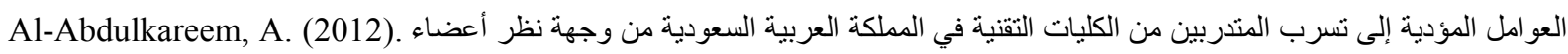
هيئة التدريب [Factors leading to trainee attrition in technical colleges in Saudi Arabia as perceived by faculty members] (Master's thesis. Imam Muhammad Ibn Saud Islamic University, Riyadh, Saudi Arabia). Retrieved from http://libback.uqu.edu.sa/hipres/ABS/ind14737.pdf

Alabdullah, M. (1995). الهذر التربوي لنظام الانتساب بجامعة الإمام محمد بن سعود الإسلامية [Educational Attrition in the Distance learning programs at Imam Mohammad bin Saud Islamic University] (Unpublished master's thesis). King Saud University, Riyadh, Saudi Arabia.

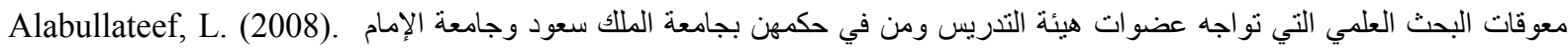
[Research obstacles faced by female faculty members of King Saud University and the University of Imam Muhammad bin Saud Islamic University in Riyadh, descriptive and analytical social study]. Retrieved from http://goo.gl/00FzzY 
AL-Dossary, S. (2008). A study of the factors affecting student retention at King Saud University, Saudi Arabia: Structural Equation Modelling and Qualitative Methods (Doctoral thesis, University of Stirling, Stirling, Scotland). Retrieved from https://dspace.stir.ac.uk/handle/1893/691

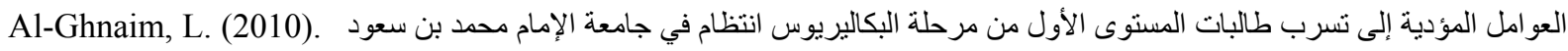
[Factors Leading to the Dropout of First-year Female Students in Full-time Undergraduate Programs at Al-Imam Muhammad Ibn Saud Islamic University] (Master thesis, Imam Muhammad Ibn Saud Islamic University, Riyadh, Saudi Arabia). Retrieved from http://goo.gl/J8S0uV

Aljohani, O. (2014). Student attrition in higher education: an exploratory study of factors influencing student retention at a tertiary English language centre in Saudi Arabia ( $\mathrm{PhD}$ thesis, RMIT University).

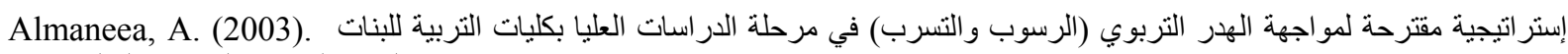
[A proposed strategy to address the educational attrition (fail and dropout) in postgraduate level in the female education colleges of the Ministry of Education]. Retrieved from http://goo.gl/9oCaUc

Alroshod, S. (2009, Nov, 15). أسباب تسرب 65\% من أعداد طلاب الكليات التقنية.. و50\% من خريجي التقنية عاطلون [Causes of attrition for $65 \%$ of the technical colleges students and $50 \%$ of technical colleges graduates are unemployed]. Al-jazirah Newspaper. Retrieved from http://www.al-jazirah.com.sa/2009jaz/nov/15/rj3.htm

Astin, A. W. (1984). Student involvement: A developmental theory for higher education. Journal of College Student Personnel, 25(4), 297-308.

Bagazi, A. (2010, Jul 10). 60\% نسبة تسرب طلاب وطالبات الجامعات خلال العامين الماضيين $60 \%$ is the attrition rate for university students in the last two years]. Asharq Alawsat. Retrieved from http://goo.gl/gYQsWq

Berger, J., Ramirez, G. B., \& Lyon, S. (2012). Past to Present: A Historical Look at Retention. In A. Seidman (Ed.), College student retention: Formula for student success (pp. 7-34): Rowman \& Littlefield, 2012.

Braun, V., \& Clarke, V. (2006). Using thematic analysis in psychology. Qualitative research in psychology, 3(2), 77-101. http://dx.doi.org/10.1191/1478088706qp063oa

Bryman, A. (2008). Social Research Methods. OUP Oxford.

Creswell, J. (2005). Educational research: planning, conducting, and evaluating quantitative and qualitative research. Pearson/Merrill/Prentice Hall.

Creswell, J. (2012). Educational Research: Planning, Conducting, and Evaluating Quantitative and Qualitative Research. International Edition: Pearson Books.

Dahan, N. (2008). Effective facilitation and students' retention in distance education. (Doctoral dissertation), University of Phoenix, Arizona, United States. Retrieved from http://goo.gl/Dy301G

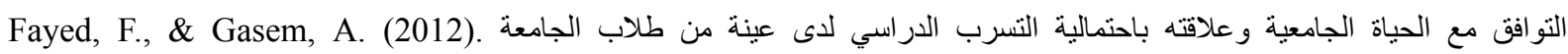
[Adjustment with university life as related to probability of dropout among the university students]. Journal of Psychological Counseling, 32, 228-273.

Felemban, W. (1986). الفاقد التعليمي في الدراسات العليا لطالبات جامعة أم القرى [Educational attrition among postgraduate female students in Umm Al-Qura University] (Master's thesis, Umm Al-Qura University, Makkah, Saudi Arabia). Retrieved from http://goo.gl/avqo82

Ghaban, M. (1999). الهدر التعليمي في جامعة الملك عبدالعزيز، دراسة وصفية تحليلية [Educational Attrition at King Abdulaziz University; descriptive and analytical study].

Hakeem, A.-E. (2007). Student's Drop-out Phenomenon in Teachers Colleges, Factors and Reasons. Retrieved from http://goo.gl/c1S1XY

Ibrahim, M., Rwegasira, K., \& Taher, A. (2007). Institutional factors affecting students' intentions to withdraw from distance learning programs in the Kingdom of Saudi Arabia the case of the Arab Open University (AOU). Online Journal of Distance Learning Administration, 10(1).

Institute of Public Administration. (2012). Institute of Public Administration. Retrieved January 7, 2014, from http://www.ipa.edu.sa/English/Pages/default.aspx

Khan, R., \& Osman, D. (2011). Factors Effecting Retention and Satisfaction among Accounting and Marketing' Major Students at Dammam Community College; an Evidence from Saudi Arabia. Paper presented at the Clute Institute International Academic Conferences, New Orleans Louisiana. Retrieved from http://goo.gl/03pouu 
Malah, T. (1994). تنسرب الطلاب من الكليات التقنية المتوسطة بالمملكة العربية السعودية]Student attrition at the secondary technical colleges in Saudi Arabia]. Message of Education and Psychology, 4, 75-116.

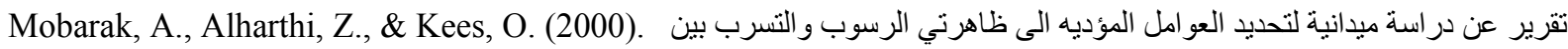
] طلاب جامعة ام القرى من وجهة نظر الر اسبين و المتسربين و اعضاء هيئة التدريس the factors leading to fail and attrition phenomenon among student of Umm Al-Qura University as perceived by the students who failed and dropped out and faculty members]. Umm Al-Qura University Journal of Educational, Social and Humanities Sciences, 12(1), 165-176.

Riyadh Economic Forum. التعليم الفني و التدريب المهني ومدى ملائمته للإحتيجات التنموية من القوى العاملة.(Technical education and vocational training, and its suitability for the development needs of the workforce]. Riyadh, Saudi Arabia: Riyadh Economic Forum.

Tinto, V. (1993). Leaving College: Rethinking the Causes and Cures of Student Attrition (2nd ed.). University of Chicago Press, Chicago, IL.

\section{Notes}

Note 1. In 2013, the Saudi Ministry of Higher Education introduced the Saudi Digital Library (http://sdl.edu.sa) as a repository for Saudi masters and doctoral theses and dissertations.

\section{Copyrights}

Copyright for this article is retained by the author(s), with first publication rights granted to the journal.

This is an open-access article distributed under the terms and conditions of the Creative Commons Attribution license (http://creativecommons.org/licenses/by/4.0/). 